\title{
OLIGARQUIZACIÓN PROFESIONAL Y DECADENCIA MUDÉJAR. LOS HERREROS MURCIANOS (SS. XIV Y XV)
}

\author{
M. ${ }^{a}$ de los Llanos Martínez Carrillo*
}

La herrería fue una actividad emblemática de los mudéjares bajomedievales murcianos vinculada al ejercicio de un tipo de poder institucionalizado; el número de los que la practicaban ${ }^{1}$ y su alto nivel técnico fueron las plataformas sobre las que sus relaciones socioeconómicas con la comunidad cristiana se intensificaron hasta convertirlos en abastecedores imprescindibles de su producto industrial y colaboradores institucionales dependientes en la vida de la morería, dentro de la cual llegaron a actuar como una auténtica oligarquía.

* Universidad de Murcia.

1. En Ávila, en el siglo XV eran el colectivo más importante después del constituido por los dedicados a la construcción, S. DE TAPIA, «LOs mudéjares de la Extremadura castellano-leonesa: notas sobre una minoría dócil (1085-1502)», Studia Histórica. Historia Medieval, VII, Salamanca, 1989, p. 117. En la zona meridional de Aragón contaban con barrios propios como el de Daroca, en el que existía una calle de las Herrerías, M. I. FALCON PEREZ, "Las manufacturas del hierro en Aragón en los siglos XIV-XV», Actas de las l Jornadas sobre minería y tecnología en la Edad Media peninsular, Fundación Hullera Vasco-Leonesa, 1996, p. 366. En Valencia, el "dret de herrería" era una exacción que afectaba, incluso, a comunidades rurales, siendo la herrería una de las profesiones más documentadas en la ciudad de Valencia, $\mathrm{J}$. Hinofosa MONTALVO, «Señorío y fiscalidad mudéjar en el reino de Valencia», Actas del $\mathrm{V}$ Simposio Internacional de Mudejarismo, Instituto de Estudios Turolenses (I.E.T.), 1991, p. 121 y «El trabajo mudéjar en Valencia medieval», Actas del VI Simposio Internacional de Mudejarismo, I.E.T., 1995, pp. 69, 73 y 77. Sobre los mudéjares murcianos hay que destacar de entre la abundante obra de J. TORRES FONTES los siguientes trabajos por su globalidad: "Los mudéjares murcianos en la Edad Media», Actas del III Simposio Internacional de Mudejarismo, I.E.T., 1986, pp. 55-66 y «Los mudéjares murcianos: economía y sociedad», Actas del IV Simtposio Internacional de Mudejarismo, I.E.T., 1992, pp. 365-393. Recientemente C. VEAS ARTESEROS, Mudéjares murcianos. Un modelo de crisis social (s. XIII-XV), Excmo. Ayuntamiento de Cartagena, 1992 y A.L. Molina Molina y M. ${ }^{2}$ C. VEAs Arteseros, «Situación de los mudéjares en el Reino de Murcia», Áreas. Revista de Ciencias Sociales, 14, Murcia, 1992, pp. 93-105. De entre las próximas morerías alicantinas, tanto geográfica como históricamente, hay que señalar los trabajos de J. HiNojOSA MONTALvo sobre Crevillente y Elche: «Crevillente: una comunidad mudéjar en la Gobernación de Orihuela en el siglo XV», IV Simposio..., pp. 307-317 y La morería de Elche en la Edad Media, Instituto de Estudios Turolenses, 1994. 
La protección genérica que los reyes dispensaron a las aljamas del reino fue deteriorándose progresivamente hasta ser algo más teórico que real, apreciándose en el siglo XV una clara oposición entre los textos reales que la desarrollaron desde el siglo XIII y la concreta y dura actuación de la mayoría de los oficiales cristianos que, en el caso de Murcia, se vio algo paliada ${ }^{2}$ por la necesidad que la ciudad tuvo de la actividad de la minoría de herreros mudéjares en ella residentes; su especialización en determinadas actividades metalúrgicas, entre las que estuvieron la fabricación de artefactos bélicos y la cerrajería-relojería, hizo de ellos un eslabón económico e institucional que se materializó en la ocupación de las funciones de alcaides de la morería de la Arrixaca, con tareas ejecutivas delegadas por el alguacil mayor del concejo de Murcia y alcaldes de la misma, con funciones judiciales internas entre su comunidad, por linajes de herreros e individualidades perfectamente identificables y analizables, cuyo estudio es posible continuar en el marco del gran avance que las investigaciones sobre el mudejarismo están experimentando desde hace dos décadas ${ }^{3}$.

El mayor nivel económico alcanzado por los herreros respecto al resto de sus convecinos, merced a su clientela favorecida por el concejo, supuso la plataforma de sustentación de su proceso de institucionalización como alcaides y alcaldes, todo lo cual les permitió atravesar circunstancias ciertamente difíciles cuando sus actuaciones surgieron envueltas en estallidos de descontento y auténtica violencia de sus convecinos luchando por defender su identidad y en coyunturas políticas de reorganización y fortalecimiento del poder cristiano, cada vez más frecuentes unas y otras desde finales del siglo XIV a ambos lados de la línea de separación del reino de Murcia y la Gobernación de Orihuela, que inexorablemente acentuaban el proceso de aculturación que vivió el mudejarismo ${ }^{4}$.

La inquietud de la morería y su comportamiento a veces traicionero estaban relacionados con su situación de pobreza sistemática y el estado con-

2. J. TORRES FONTES, «Los Mudéjares», Estampas Medievales, Academia Alfonso X El Sabio, 1988 , p. 302.

3. M. GONZÁLEZ JIMÉNEZ reconoce la existencia en Sevilla de grupos familiares o familias amplias, muy bien definidas por su número y su actividad profesional, entre ellos los herreros Blanco, de los que Çayde fue el último alcaide de la aljama sevillana, «El trabajo mudéjar en Andalucía. El caso de Sevilla (siglo XV)», Actas del VI Simposio..., pp. 41-42 y apéndice I. La amplia bibliografía sobre el tema fue sistematizada básicamente por J.C. DE MiGUEL RODRíGuez, Los mudéjares de la Corona de Castilla, Cuadernos de Investigación Medieval, n." 8, 1988, y está siendo actualizada por M. EPALZA y L.F. BERNABE PONS, «Bibliografía de mudéjares y moriscos, I», Sharq al-Andalus. Estudios Mudéjares y Moriscos, n." 12, TeruelAlicante, 1995, pp. 631-655.

4. M. ${ }^{\mathrm{a} T}$. FerReR Y MALLOL, Les aljames sarraïnes de la Gobernació d'Oriola en el siglo XIV, C.S.I.C., Barcelona, 1988. M. MARTínEZ MARTínEZ, «Colaboracionismo castellano-aragonés ante la violencia mudéjar (1390)», Aragón en la Edad Media, X-XI, pp. 589-601. 
creto de las relaciones con Granada en su frontera castellano-murciana, incidiendo todo ello en una población cada vez más reducida ${ }^{5}$, cuya supervivencia dependía en buena manera de la aceptación o no de inmigrantes en su seno; si además el conjunto de la ciudad atravesaba tiempos de profunda revulsión, las dificultades de alcaides y alcaldes de la morería eran máximas, así como la formación de banderías en la misma en oposición por distintas formas de subsistencia y poder, como demuestra la propia analítica de unos hechos que fueron frecuentes en el siglo XV y están perfectamente documentados.

Un primer ejemplo de este proceso lo proporciona el nombramiento de Mahomat Borrás como alcaide el 20 de septiembre de $1396^{6}$, hecho que se produjo en condiciones generales muy alteradas, las cuales ponen de manifiesto que la crisis interna de la morería estaba agudizándose a tenor de la propia crisis urbana. La figura institucional que representó durante casi dos décadas Mohamed Borrás tenía la intrínseca debilidad de ser pieza interpuesta entre la comunidad mudéjar de la que formaba parte y el concejo de la ciudad del que dependía; de ahí la habilidad que los alcaides tuvieron que desarrollar para sobrevivir en el cargo, especialmente difícil en este personaje por la época de profunda crisis que supusieron los finales del siglo XIV y comienzos del XV.

Dividida la ciudad en una lucha de bandos desde 1391, a la altura de 1396 una fracción de ella estaba acantonada dentro de la ciudad frente al rey y arruinada materialmente en manos de un reducto local; reflejo de esta situación fue el cambio que se operó en la alcaidía, producido cuando Enrique III reforzaba los poderes ordinarios del adelantado mayor que había impuesto, ordenando que fuese juez de todo tipo de asuntos civiles a través de su lugarteniente; la orden real se conocía días después de que el anterior alcaide y los viejos de la morería, reforzando moralmente y jurídicamente su postura, se quejaran ante el concejo ciudadano de las prendas hechas por los alguaciles cristianos para cobrar deudas pendientes; la exigencia concejil de que la morería entregase 30 florines el dos de septiembre, haciendo caso omiso de la petición de alcaide y viejos, fue seguida por el nombramiento como nuevo alcaide de Mahomat Borrás, realizado por los jurados y alcaldes concejiles en reunión de la aljama celebrada en la mezquita ${ }^{7}$.

5. Veinte vecinos en 1461, Actas Capitulares (en adelante A.C.) 1460, f. 91r (1461-V-2), aunque posteriormente se perciba una tenue recuperación, J. TORRES FONTES, «Los mudéjares murcianos...", Actas del IIl Simposio..., p. 65.

6. A.C. 1396, f. 73v (1396-IX-28). Primeros análisis de los hechos en M. ${ }^{a}$ Ll. MARTínez CARRILLO, Revolución urbana y autoridad monárquica en Murcia durante la Baja Edad Media (1395-1420), Universidad de Murcia-Academia AIfonso X El Sabio, 1980, pp. 65-66; J. TORREs FONTES, Estampas Medievales, pp. 338-341 (edición anterior en 1380).

7. A.C. 1396 , f. 59v y 68r (1396-IX-2 y 16). M. ${ }^{a}$ Ll. MARTínez CARRILlo, Manueles y Fajardos. La crisis bajomedieval en Murcia, Academia Alfonso X El Sabio, 1985, pp. 338-341. La asesoría de los 
Fue un nombramiento impuesto por la facción acantonada y controladora del concejo de la ciudad, Io cual explica la oposición encontrada por Mahomat Borrás y la denuncia ante el concejo de la agresión que sufrió por parte de tres de sus convecinos, denuncia que estuvo respaldada por " ...la mayor parte de los moros de la aljama...", no todos, puesto que una porción de ellos fueron los que apoyaron a los tres agresores, cabezas visibles del descontento que se había manifestado infructuosamente unos días antes en la persona del alcaide destituido y el consejo de viejos, intentando sin éxito saldar unas deudas fiscales. La parcialidad del alcaide Mahomat Borrás y sus contrarios era reflejo de las existentes en la sociedad cristiana como demuestra que, una vez pacificada ésta en 1399 e impuesta la autoridad real en la misma a través de altos oficiales regios, la morería se mostrase compacta en sus pretensiones de defensa jurisdiccional y aplicación de la "cunya e xara", en unos hechos desarrollados en 1401 en torno al apresamiento de unos moros aragoneses que, según el adelantado, pretendían huir a Granada, y según la morería sólo eran potenciales nuevos vecinos, la razón de la comunidad mudéjar fue reconocida y los moros liberados de la prisión del nuevo alcaide Ahmed Exahuex ${ }^{8}$.

El fenómeno se repitió pocos años después con las mismas características. Dos facciones en la morería se vuelven a apreciar entre 1410 y $1411^{9}$, para las que la política de protección concejil al artesanado se conectó con una problemática instalación en la morería de maestros forasteros, que no

consejos de viejos en las aljamas valencianas, especialmente en relación con los alamines en M.V. FEBRER ROMAGUERA, «Antecedentes y configuración de los consejos de viejos en las aljamas de moros valencianas», Actas del V Simposio Internacional de Mudejarisino, I.E.T., 1991, pp. 154 y 165. Los contingentes demográficos, el fisco y el proceso de aculturación mudéjar en M.A. LADERO QUESADA, «Los mudéjares de Castilla en la baja edad media», Actas del I Simposio Internacional de Mudejarismo, CSIC-Diputación Provincial de Teruel, 1981, pp. 349390 y Los mudéjares de Castilla y otros estudios de Historia medieval andaluza, Granada, 1989. La emigración de raíces fiscales, generalmente reconocida por la historiografía, en el caso aragonés está recientemente tratada por M. ${ }^{a}$ L. LEDESMA RUBIO, «La fiscalidad mudéjar en Aragón» y P. PÉREZ VIÑuAlEs, «Presión fiscal y emigración; algunos ejemplos de aljamas mudéjares aragonesas», Actas del V Simposio..., pp. 14 y 75-86. Para el medio rural del reino de Murcia, M. RODRíguez LLOPIS, «Población y fiscalidad de las comunidades mudéjares del reino de Murcia (siglo XV)», Actas del III Simposio Internacional de Mudejarismo, I.E.T., 1986, p. 45. Es de destacar el reconocimiento que del problema de la despoblación, relacionado con las disensiones internas, hacen los propios mudéjares, en este sentido véase R. SALICRU Y LLUCH, «Sarraïns desaveïnats d'Elx a mitjan segle XIV (1449) segons llur propi testimoni: dificultats economiques y conflictivitat interna de la moreria», Sharq al-Andalus. Estudios Mudéjares y Moriscos, 12, Teruel-Alicante, 1995, pp. 32 y 36-37.

8. A.C. 1400 , f. 55v (1401-VIII-8) y 74r (1401-IX-3). J. TORRES FoNTES, «Vaivén musulmán murciano», Murgetana, 86, Murcia, 1993, p. 12.

9. A.C. 1410, f. 2v y Libro de Protestaciones 1410-1411, f. 1v (1410-VII-22) y A.C. f. 7 r (1410-IX20). M.'LI. MartíneZ Carrillo, Revolución..., pp. 62 y 225. 
eran bien recibidos por los ya existentes, porque se negaban a abrirse a una competencia, excesiva para el raquitismo del mercado local.

El alcaide y herrero, maestre Mahomad, que en 1407 era uno de los veinte artesanos murcianos excusados del pago de "monedas" y otros impuestos reales, siendo él el único mudéjar, lo cual demuestra su preeminente posición social ${ }^{10}$, había gestionado la instalación en la morería murciana de tres artesanos de Vélez, maestre Abrahim, carpintero y albañil, maestre Mahomad, tornero, y el calderero Abdallá, y se disponía a hacer otro tanto con los hermanos Çad y Heça Torán, herreros de Hellín, quienes junto a dos criados, uno herrero y otro cuchillero y sus respectivas familias y algunos más procedentes de Mula llegarían a abrir hasta ocho tiendas nuevas; el problema surgió porque entre las condiciones de establecimiento estaba la concesión concejil a Heça de "un pedazo de calle", en la que hiciese una buena tienda, anexa a las casas que el alcaide había comprado en su nombre, situadas a la entrada de la morería y junto a las casas que el herrero judío Yahuda tenía inmediatas; la aljama mudéjar había consentido la entrega del callejón, previamente abandonado por Abdullá, un moro emigrado a Alguazas, tras lo cual el alcaide pidió la corroboración concejil reconociendo que había personas en la morería que se oponían a la instalación del grupo de artesanos, fundamentalmente los de Hellín.

La oposición a la instalación de estos artesanos la encabezaba un grupo, "...et a son de aljama lo que non eran...", con los poderes que la aljama tenía para resolver asuntos internos decidieron otorgar el callejón a Adutar, un moro no avecindado, según el alcaide, con la intención de buscar el enfrentamiento con el adelantado, a quien competía el control de los moros "descaminados" en función de la vigilancia fronteriza, como alcalde que era entre moros y cristianos, especialmente importante en los tiempos que culminaban en la campaña de Antequera; el alcaide, maestre Mahomad, argumentaba que aunque aquel grupo hubiese ostentado legítimamente los poderes de la aljama, "...lo que non ha, el algama non tienen poder de dar et vender la call real sy non vos dichos señores...".

Bajo un planteamiento puramente jurídico institucional, el problema real que subyacía no era el urbanístico, sino el de dos sectores sociales en la morería que entendían de distinto modo la necesidad de repoblación artesanal de la misma, así como las directrices que se le debían imprimir; en estas circunstancias el tumulto callejero ocurrido el 19 de septiembre de 1410 estaba servido. En aquella ocasión, el alcaide y los dos jurados de la morería, junto a siete moros de la misma miembros de la aljama, denunciaron ante el alcalde de adelantado las agresiones orales que habian sufrido en la mezqui-

10. A.C. $1407-1408$, f. 73 r (1407-XII-2). 
ta por parte del alcaide, maestre Mahomad, y sus dos hijos, especialmente las dirigidas al jurado Yuçaf Alasfi y al alcalde Hamet Caher, a los que amenazaron de muerte; los denunciantes decían que el alcaide y los suyos serían los causantes de la despoblación de la morería de seguir ocupando el cargo, por lo que pidieron su inmediata destitución y el nombramiento por el alcalde de adelantado de otro alcaide que contase con la aprobación de la aljama, según estipulaba un privilegio de Fernando IV de $1304^{11}$.

No se trató solamente de una burda pelea impregnada de palabras malsonantes; más que eso fue el enfrentamiento entre dos sectores sociales, el partidario de abrir la morería a una repoblación cualitativa de artesanos, personificado por el alcaide Mahomat y respaldado por el alcalde de adelantado, que no consintió en su destitución, y los más conservadores y temerosos de una competencia económica que degenerase en la ruina y emigración de los menos favorecidos: frente al pragmatismo del alcaide, hecho a convivir con la sociedad cristiana y crear y defender su patrimonio junto a ella, como demuestra su participación en el arrendamiento de almojarifazgo de la aduana de la morería ese mismo año ${ }^{12}$, se levantaba el pesimismo intransigente de los oficiales y la aljama, entre los que significativamente estaban Hamet y Mahomad Alfellini, miembros de otra familia de herreros fundamental en el siglo XV, que años después conseguirían ocupar la alcaldía durante dos generaciones, representadas por Abrahim y Çad Alfellini.

En 1410 el alcalde de adelantado debió de adoptar una solución salomónica manteniendo al problemático maestre Mahomad como alcaide de la morería, tras aproximar su postura a los disidentes; así se desprende de la comparecencia de este último junto a los dos jurados, Jusaf Alazfi "el calderero" y Çale Albixtara o Abixcardi, anteriormente enfrentados a él, pidiendo que les fueran devueltas las ropas de cama incautadas para contribuir al pago de pedidos y monedas y haciendo suya la tesis del despoblamiento y pobreza de la aljama que anteriormente habían sustentado sus rivales, "...ay muchos moros que mal pecado non tienen ropa en que se echen...", pobreza y despoblamiento que era una situación arrastrada y agravada desde el siglo XIII ${ }^{13}$.

11. Medina del Campo, 1305-IV-20, Colección de Documentos para la Historia del Reino de Murcia (C.O.D.O.M.), V, 1980, doc. XLV, pp. 48-50. A.C. 1410, f. 6v y Libro de Protestaciones 14101411, f. 5v (1410-IX-19). J. TORRES FONTES, Estampas medievales..., pp. 335-338 y «Los mudéjares murcianos en el siglo XIII», Murgetana, 17, 1961, pp. 13-28.

12. Libro de Protestaciones 1410-1411, f. 18r (1410-XI-18).

13. A.C. 1410 , f. 9r y Libro de Protestaciones 1410-1411, f. 8r (1410-X-18). J. TORRES FON'lES, Estampas Medievales..., pp. 354-355. En 1335 Alfonso XI, a petición del concejo ciudadano, autorizaba a los moros de la Arrixaca de Murcia a acensar 15 tahúllas de tierra según los usos cristianos, para así contribuir a su subsistencia porque "...los nuestros moros de la Arrexaca de y, de Murçia, son muy pobres et menguados en manera que non pueden pagar nin conplir los nuestros pechos...", Valladolid, 1335-I-10, Cartulario Real, Era 1352-1382, f. 120 r. 
El autoritarismo concejil emanado del ordenamiento aprobado en 1408 y completado en 1412 se plasma en el penoso cuadro de despoblación, aculturación y sometimiento de la morería que el propio alcaide y los oficiales de la misma describían en octubre de 1410, cuando los enfrentamientos de un mes antes ya habían sido acallados y maestre Mahomad confirmado en la alcaidía; vulneración de los privilegios reales por la propia miseria de la población mudéjar, que para cumplir sus obligaciones en el más oneroso de los impuestos reales, los servicios, "...buscan sus maneras como Dios mejor les ayuda e a ellos se les entiende, obligándose a algunos christianos por los contractos que con ellos fazen, a las veces con cartas desaforadas diciendo que renunçian los preuillejos que an del dicho señor rey e de los reyes onde el viene, syn tener mientes a ello por ser omes symples miserables, syn saber ni entender las tales graçias e merçedes e preuillejos..."; renuncias escritas que posteriormente los acreedores hacían utilizar para cobrar, embargar y proceder con cualquier sistema de presión a través de los alcaldes concejiles, siendo ésta una causa de emigración incontestable de esta minoría que, en modo alguno, hoy día puede ser catalogada como raza ${ }^{14}$.

La larga alcaidía de maestre Mahomad se caracterizó por su indisoluble unión institucional al concejo, a cuya sombra controló la morería e hizo su patrimonio, sorteando con habilidad las crisis internas que sociedad cristiana y mudéjar atravesaron, siendo entonces cuando las fuentes se hacen más permeables, especialmente intensas como consecuencia de las predicaciones de san Vicente Ferrer; buena prueba de ello fue la obtención de un permiso concejil en 1411 para comunicar su taller con la ciudad cristiana, con la condición de que lo cerrase hacia la morería, cuando el barrio iniciaba un irreversible proceso de aislamiento; simultáneamente pedía que se le renovase la franquicia que obtuvo al instalarse en la ciudad, posiblemente unos diez años antes, verosímilmente condicionado por el concejo en aquellas circunstancias a su conversión, pues su nombre empieza a desaparecer de las fuentes a partir de aquellas fechas ${ }^{15}$. Su patrimonio personal ya era notable en 1410, como desmuestra que tuviese una heredad en la acequia de Alguazas que para ser segada necesitaba de sus propios mozos y dos contratados temporales, unas cuatro personas, cuyas faenas en la pascua de Pentecostés de 1411, tras las predicaciones de san Vicente, le supusieron el apresamiento de los segadores y la incautación de unas prendas de ropa en su casa como

14. A.C. 1410 , f. $10 \mathrm{v}$ y Libro de Protestaciones 1410-1411, f. 9r $(1410-X-25)$; M. ${ }^{a} \mathrm{C}$. VEAS AR'I'ESEROS presenta el problema como una cuestión económica y de "degradación resignada de su particular idiosincracia", Mudéjares murcianos..., p. 17 y apéndice documental VII, A.L. Molina Molina y M. ${ }^{a}$ C. VEAS ARTESERos, «Situación de los mudéjares...», pp. 96 y 102. Los embargos fiscales como causa de cambio de jurisdicción, J. TORRES FONTES, «Los mudéjares murcianos; economía y sociedad», p. 371.

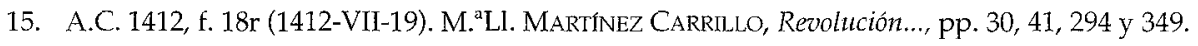


pago de la sanción impuesta ${ }^{16}$. Tanto el capital con el que participaba en el arrendamiento del almojarifazgo, como las tierras que poseía y la calidad y variedad de las ropas que se le incautaron, demuestran que su trayectoria a la sombra del poder cristiano se había materializado en un estatus excepcional en la morería, que no era posible sin una sumisión total en momentos en los que el concepto y la praxis del poder pasaban inexorablemente por la identificación con la sociedad cristiana.

El enfrentamiento de su hijo junto a un grupo de personas armadas que se oponían al ahorcamiento de un moro, vecino de algún territorio de señorío eclesiástico, juzgado y condenado por asesinato por alcaldes concejiles, fue la respuesta a la confrontación institucional entre la sociedad mudéjar en crisis y su alguacil Hamed Exaues por un lado, y la justicia cristiana en su doble vertiente de concejil y eclesiástica por otro ${ }^{17}$, lo cual llevó las cosas hasta la proclamación de "entredicho" en la ciudad por el obispo y al tumulto ciudadano, en el que participó un fraile franciscano junto a los mudéjares levantiscos que intentaban liberar al reo, comprometido en sus intentos de evangelización y conversión de la minoría, tal era el entramado casuístico de las tensiones sociales en los comienzos del siglo XV.

En los momentos en los que la comunidad mudéjar acusaba más intensamente su pérdida de identidad o la violación de su estatuto, era su consejo de "moros viejos" el que esgrimía sus derechos frente al concejo de la ciudad de forma continuada hasta los finales del siglo XV. En 1469 "...la aljama de los moros viejos omnes buenos de la morería..." presentó ante el concejo a través de su alcalde, el herrero Abrahim Alhajar, una fuerte denuncia contra la agresión que su territorio sufrió a manos de un grupo de judíos armados que, encabezados por don Moisés Aventuriel y don Moisés Allori de Cartagena, buscaban a dos moros de su propiedad que habían desaparecido después de entrar a la morería tras los servicios de una prostituta mudéjar vecina de la misma; el grupo judío, sin autoridad concejil, entró violentamente en el arrabal cuando, ya de noche, estaban cerradas sus puertas y registraron todas sus casas sin que los mujéjares llegaran a defenderse por sorpresa e inferioridad, "...estovimos en tienpo de ge lo regestyr..." 18; la emigración pacífica unas veces y la huida de cautivos y esclavos otras, eran tan continuas en los finales del siglo XV que los mudéjares veían permanentemente amenazada su seguridad estatutaria, si las sospechas que recaían sobre su complicidad se materializaban en los registros de sus casas sin contar con las preceptivas licencias concejiles y la presencia en los mismos de alcaldes y alguaciles

\footnotetext{
16. A.C. 1410 , f. $34 \mathrm{v}$ y Libro de Protestaciones $1410-1411$, f. $33 \mathrm{v}$. M. ${ }^{\mathrm{a} C}$. VEAS ARTESEROS, Mudéjares murciantos.., apéndice documental VIII.

17. A.C. 1412 , f. $17 \mathrm{v}$ (1412-VII-26) y 20r (1412-VII-31).

18. A.C. 1469, f. $73 r(1469-X I I-16)$.
} 
cristianos sin lo cual, en aquella ocasión, la aljama consiguió que el concejo los eximiese de pena si, en su defensa en el futuro, herían o mataban a algún agresor.

Todos estos hechos demuestran que las tensiones entre familias son uno de los hilos conductores de la problemática social de las comunidades mudéjares; se manifestaban en puntuales situaciones que impulsaban las dificultades socioeconómicas y las ambiciones de poder, que a pesar de la pobreza, casi miseria, de estas minorías podían desarrollarse entre los elementos mejor situados, en este caso los herreros. El estudio de las familias mudéjares que generaron más actividad interrelacionada con los cristianos se hace posible a través de documentos básicamente administrativos, los cuales permiten reconstruir varias generaciones en un coherente proceso evolutivo de las mismas, así como conocer de forma cualitativa la variedad, nada despreciable, y la suma modestia de los productos que estuvieron saliendo de sus herrerías, hasta los años setenta del siglo $\mathrm{XV}$, cuando los encargos concejiles empezaron a derivar hacia herreros cristianos, conversos y posiblemente herederos de los anteriores mudéjares; se trató siempre de un comercio local, en modo alguno comparable al internacional desarrollado por los mudéjares valencianos que, mucho más numerosos y ricos, llegaron con sus productos hasta la misma Italia ${ }^{19}$.

\section{Alfajar, Alhajar o Alaycar}

Tres generaciones de miembros de este auténtico clan de mudéjares se pueden vertebrar a lo largo del siglo XV.

Mahomad y Abdallá representan la primera generación bien documentada de esta familia de torneros y herreros, posibles hijos de un Muhammad, lo suficientemente importante en 1418 como para ser nombrado alcalde mayor de las aljamas en un contexto que Torres Fontes calificó de transición de la persecución a la tolerancia ${ }^{20}$; entre los años 1432 y 1438 Mahomad estuvo exento por privilegio real de pago de impuestos y fue, por lo menos, "alfaquí mayor" de la aljama, todo ello compatibilizado con su cotidiano trabajo en el taller ${ }^{21}$. Abdallá era herrero y estuvo igualmente exento del pago de impuestos por concesión real, documentada entre 1432 y 1436, cuando lleva-

19. J. Guirali-HadzL̈ossif, Valencia puerto mediterráneo en el siglo XV (1410-1525), Edicions Alfons El Magnànim, Valencia, 1989, p. 442.

20. J. TORRES FONTES, «El alcalde mayor de las aljamas de moros de Castilla», Anuario de Historia del Derecho Español, XXXII, 1962, pp. 149-151.

21. M. ${ }^{2}$ LI. MaRTÍNez CARRILLO, «'Servicios' castellanos y política municipal (1420-1450)», M.M.M. XIV, 1987-1988, p. 288, J. TORRES FONTES, «Vaivén musulmán murciano», Murgetana, 86, 1993, p. 14 . 
ba ya mucho tiempo trabajando para el concejo en la reconstrucción de puertas de la muralla, cámara de la corte, cárcel, peso de la harina y porche de la plaza de santa Catalina, elaborando todo tipo de materiales hasta $1446^{22}$.

Galip o Galín y Abrahim, ambos herreros, eran hijos de Abdallá, el primero de ellos conocido sobre todo como recaudador de monedas en la morería en los años cuarenta ${ }^{23}$. Su hermano Abrahim fue por esos mismos años "maestro de hacer lombardas", alcanzándose con él la culminación del proceso de institucionalización de los Alhajar, paralelo a su nivel económico, simbolizado en la propiedad de las casas que habian sido de su padre a las que añadió otras en las que tenía su obrador, las cuales fueron ampliadas en 1452 con "un pedaço e rincon" de calle anexo, en un proceso de extensión que le fue discutido por el ballestero Bartolomé, que la había ocupado hasta entonces, litigio que tuvo que dirimir el adelantado Pedro Fajardo ${ }^{24}$; en 1469 era alcalde y poco después el concejo ordenó pagarle $1.000 \mathrm{mrs}$. anuales por ser "maestro mayor de facer las lonbardas" y "otros tyros de poluora" para que no cumpliese la amenaza de emigrar "por ser pobre"; su decadencia personal fue el mejor símbolo de la decadencia de su propia comunidad.

El rastro de Abrahim puede seguirse hasta 1479, cuando ya debía de ser un hombre muy viejo que aún conservaba la alcaidía, dignidad en la que le sucedería un inconcreto personaje, conocido en 1496 como maestre Alfajar ${ }^{26}$.

\section{Alfallini o Alfellini}

Bien conocidos desde principios del siglo XV, cuando Hamet y Mahomad formaron parte del grupo de vecinos de la morería que en 1410 encabezaron la oposición al alcaide maestre Mahomad, como ya se ha visto.

Desde 1424, por lo menos, hasta su muerte hacia 1438, un nuevo miembro de la familia, Abrahim, está documentado a través del pago de un florín de censo por la casa y los dos obradores de herrería que ocupaba en el barrio moro de la Arrixaca, siendo al mismo tiempo alcaide de la misma ${ }^{27}$. Si-

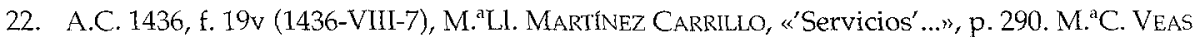
ARTESEROS, La Hacienda Concejil Murciana en el siglo XV (1323-1482), Universidad de Murcia 1988 (Microforma), Apéndices documentales (A.d.) de 1429-1430 a 1445-1446 (1446-V-14).

23. M. 'C. VEAS AR'IESEROS, A.d. 1441-1442 (1442-XI-7),

24. A.C. 1452, f. 40r (1452-XII-5), M."C. VEAS ARTESEROS, A.d. 1446-1447 (1447-VII-30 y VIII-13 y 29), 1461-1462 (1461-XII-27 y 1462-I-9).

25. A.C. 1469 , f. 73 r (1469-XII-16); 1470, f. 80r (1471-I-5) y 1471, f. 21v (1471-VII-20).

26. A.C. 1477, f. 123 r (1477-V-6), 1479, f. 45v (1479-VII-31) y 1496, f. 77r (1496-XI-29).

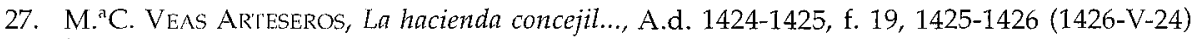
hasta $1438-1439$, f. 348 y 440 . 
multáneamente, en los últimos años de la vida de Abrahim, otro miembro de la misma familia, Çad, estaba exento del pago de impuestos por privilegio real como garbillador, conocedor y limpiador de metales con una criba o garbillo; el dato es interesante por cuanto el trabajo de un herrero reconocido y necesario permitía una relativa especialización en el seno de la familia y la comunidad; por otra parte Çad, prácticamente desconocido fuera de estos datos fiscales ${ }^{28}$, no estaba vinculado por sí mismo al pago del censo al concejo, mientras que Abrahim, alcaide y censualista no aparece como exento de monedas siendo, acaso, ambos miembros de dos generaciones sucesivas como padre Abrahim e hijo Çad.

El último elemento conocido de la familia es Hamete; con él ya no es posible seguir las relaciones institucionales y económicas que los ligaban al concejo, de tal modo que su presencia resulta esquemáticamente datada en una descripción de lindes que afectaba a su casa ${ }^{29}$.

\section{Cheleni o Chelvi}

Herreros, cerrajeros y relojeros, los Cheleni presentan el mejor caso de evolución adaptada a las necesidades sociales y de mercado, dentro de los modestos parámetros en los que siempre se movió la herrería murciana. Los relojes mecánicos, con raíces europeas en la segunda mitad del siglo XIII, no tuvieron implantación definitiva hasta los años treinta del siglo XIV ${ }^{30}$, y en las principales ciudades hispánicas hasta los finales de dicha centuria, no llegando a Murcia el trascendente invento mecánico-ideológico, al que la familia Cheleni estuvo vinculada, hasta mediados del siglo XV.

Su primer miembro reconocido fue Mahomad, herrero y cerrajero que ya tenía en 1439 la confianza concejil que demuestra que fuese recaudador de monedas y antes, en 1432, fabricara para el concejo un hierro "con señal de corona", trabajo de precisión con el que quedarían legitimados los cánones de las medidas utilizadas por el concejo para posteriormente fabricar todas las usadas en la ciudad; además se le calificaba de "cerrajero" al elaborar un cerrojo con llave de la Puerta del Puente ${ }^{31}$, cosa que hicieron antes y después que él muchos otros artesanos de su especialidad que nunca fueron calificados documentalmente nada más que por herreros.

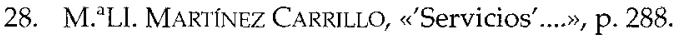

29. A.C. 1478 , f. $15 \mathrm{v}$ (1478-VII-7).

30. J. GIMPEL, La revolución industrial en la Edad Media, Taurus, 1982, pp. 120-121.

31. M. ${ }^{\mathrm{a} C}$. VEAS ARTESEROS, La hacienda concejil..., 1431-1432 (1432-III-16 y V-5); 1438-1439 (II-25); 1441-1442 (1441-VII-4); 1449-1450 (1450-IV-20).
} 
Se plantea, no obstante, la necesidad de marcar el camino por el cual el cerrajero se convirtió en "maestro de hacer reloxes" y la explicación podría venir de la mano de Alemán, maestro de hacer tijeras, navajas y "relonjes", que en 1436 recibía del concejo licencia para instalarse en la Torre de los Pellejeros 32 ; es la primera noticia cierta de este tipo de actividad en la ciudad, la cual relaciono con la instalación del "medio reloj" de 1449 que no debía de ser un completo artilugio mecánico. Alemán no fue el único cristiano vinculado a los orígenes del reloj en Murcia; también en 1459 maestre Juan, relojero, debió de ser el artífice principal de la definitiva instalación ${ }^{33}$; sólo las dificultades de la vida ciudadana que incidían en la escasez y precariedad del artesanado local, explican que fuese una familia de mudéjares la que terminó controlando el funcionamiento del reloj hasta 1479.

La habilidad de Mahomad con el engranaje de los cerrojos se compaginaba con todo tipo de actividades profesionales y de confianza, que iban desde la recaudación de impuestos a ser enviado por el concejo a Alicante en 1446 para examinar las lombardas allí existentes, antes de procederse en Murcia a la construcción de una necesaria para la campaña de asalto a Molina, donde se dirimía un episodio de la permanente lucha de banderías locales $^{34}$. Su desaparición y sustitución por una nueva generación se produjo en los años cincuenta, pues él fue el maestro de hacer relojes al que se le encomendó el cuidado del medio reloj, ya instalado en Santa María en 1449, no siendo hasta 1460 cuando un nuevo Mohamad Chelvi trabajó otra vez en la instalación y mantenimiento del reloj definitivo ${ }^{35}$.

Una segunda generación está representada por Mahomad (II), vinculado a la puesta en marcha del reloj como constructor primero y luego mantenedor desde 1460, para el cual empezó haciendo unas ruedas, barras, aldaba y otras piezas ${ }^{36}$. En una de esas actividades se le denominaba "Mahomadico Cheleni, el mismo diminutivo familiar con el que se denominó en 1447 al encargado de transportar con un asno los materiales para la construcción de una lombarda, los "aljezones" para las fraguas y el hierro necesario, desde la

32. A.C. 1435, f. 70r (1436-IV-28). Su situación es la misma vivida en Teruel con posterioridad por Sebastián de Canyamache, que instaló el primer reloj mecánico en dicha ciudad en 1483, J.J. Morales GOMEZ y M. ${ }^{2}$ J. TorreblanCA GaSPAR, «Tiempo y relojes en Teruel en el siglo XV", Al profesor emérito Antonio Ubieto Arteta en homenaje académico, Univ. de Zaragoza, 1989 , pp. 455 a 460.

33. A.C. 1459 , f. 16r (1459-VII-28).

34. A.C. 1446 , f. 9r (1446-VI-28). M. ${ }^{a}$ C. VeAs ARTESEROS, La hacienda concejil..., A.d. 1438-1439 (1439-II-25); 1445-1446 (1446-VI-16) y 1446-1447 (1446-VI-28) y Mudéjares murcianos..., p. 61.

35. A.C. 1449 , f. $40 \mathrm{v}(1149-X I I-2)$ y 1459 , f. $97 \mathrm{v}(1460-\mathrm{V}-31)$.

36. En colaboración con Çad Alcaçis, A.C. 1459, f. 97v (1460-V-31) y solo a partir de entonces, 1462, 13r (1462-VII-7). J. TORRES FONTES, «El reloj. V centenario de la consagración de la Catedral de Murcia», B.I.M.M., XVII, Ayuntamiento de Murcia, 1967, pp. 123-130. 
judería donde se distribuía al alcázar donde estaba instalado el taller ${ }^{37}$; entonces era un aprendiz que trabajaba junto a su padre, el encargado de traer de Alicante el esquema de lombarda que en Murcia se construyó en el verano de 1447. El mantenimiento del reloj le proporcionó, además, un salario de $2.000 \mathrm{mrs}$. anuales y aguinaldos, y la concesión de una pequeña parcela de tierra en las cavas, próxima a la puerta de la Noguera, por la que pagó anualmente $20 \mathrm{mrs}$. de censo hasta su muerte en 1467, siendo desde entonces sus herederos Alí y Çad los que se hicieron cargo, tanto del reloj como del pago del censo.

De sus dos hijos muy pronto fue Alí su sustituto en el reloj y en el cobro del salario y otros emolumentos inherentes a él, excepto el censo de la tierra que pagaron siempre ambos hermanos. Con Alí, los Cheleni se habían convertido en unos especialistas que, desde la cerrajería en la primera generación, llegaron al mantenimiento de la relojería por parte de esta tercera, tanto en Murcia como en Lorca, ciudad a la que hizo un viaje de ocho días en 1470 para "adobar el relox", estando al cargo de esta función hasta que en el cambio administrativo de junio de 1479 fue sustituido en vida por Antón de Viveros ${ }^{38}$; la causa estuvo en la crisis interna y definitiva de la morería que redujo el número de herreros por emigración o conversión, hasta dejar el oficio en manos cristianas, lo cual explica la tardía fundación de una cofradía de herreros en la ciudad, que no tuvo lugar hasta 1489.

\section{Mambrón}

Es la única familia de artesanos metalúrgicos no herreros que tienen una cierta entidad como caldereros durante la primera mitad del siglo XV.

Ali, el primero conocido, se estableció en la Arrixaca en 1393 con su mujer, recibiendo ayuda para casa y exenciones fiscales tan fundamentales como la de monedas, porque entonces era él el único calderero existente en la ciudad ${ }^{39}$; su instalación se hizo definitiva de tal modo que en 1407 pagaba $9 \mathrm{mrs}$. de censo al concejo por la casa que éste le proporcionó, luego ampliada hasta convertirse en dos "solares" u "obradores" situados en el área occi-

37. A.C. 1463 , f. $18 \mathrm{v}$ (1463-VII-5). M. ${ }^{a} \mathrm{C}$. VeAs ARTESERos, La hacienda concejil..., A.d. 1447-1448 (1447-VI-26 a VII-22).

38. A.C. 1468 , f. 56 r (1468-XII-20); 1469 , f. $90 \mathrm{v}$ (1470-II-16) y 1478, f. $143 \mathrm{r}$ (1479-II-27) y M. ${ }^{a} \mathrm{C}$. VeAs ArTeseros, La hacienda concejil..., A.d. 1468-1469, f. 1058 y 1471-1472, f. 1196. El entorno artístico y familiar de Antón de Víveros en J. TORRES FONTES, «Escultores, cerrajeros y herreros", Estampas de la vida murciana en la época de los Reyes Católicos, Academia Alfonso X El Sabio, 1984, pp. 201-206.

39. A.C. 1392, f. 245r (1393-III-20). M. al. MarTínez Carrillo, Manueles y Fajardos. La crisis bajomedieval en Murcia, Academia Alfonso X El Sabio, 1985, p. 42. 
dental del arrabal y continuó pagándolos hasta su probable muerte en $1439^{40}$.

Su sucesor, Abdallá, estuvo pagando el censo de los obradores hasta que deja de haber noticias documentales de ello en los libros de mayordomo en $1452^{41}$.

Sin duda, su clientela estaba asegurada a través de la fabricación y venta de utensilios domésticos a la sociedad local, sobre todo culinarios, de los que el concejo participó anecdóticamente adquiriéndole "calderas" para sacar agua del pozo de la Casa de la Corte, "calderos" para regar el suelo de las estancias de la misma y cántaras de "arambre" o latón para tener agua o vino disponibles en el consistorio. Con el paso del tiempo la segunda generación representada por Abdallá alcanzó un relativo nivel económico, puesto que estaban en condiciones de proporcionar al concejo carbón, que el mismo Abdallá se encargaba de fabricar, o dos cahíces de trigo para abastecimiento de la gente de armas ${ }^{42}$, cantidad que demuestra que la alimentación familiar estaba asegurada al margen de penurias y le permitía una ampliación de sus actividades, desde la artesanía inicial al comercio a niveles muy modestos. A partir de mediados de siglo se les pierde la pista en las fuentes, bien por ruina y emigración, bien por conversión.

\section{Mexía}

Las noticias que quedan de ellos perfilan una familia proveniente de Belmonte donde habían sido vecinos, víctima de la crisis y el desarraigo; la llegada a Murcia de mercaderes y buhoneros procedentes de tierras del Marquesado de Villena fue constante en relación con el comercio del trigo y la lana, entre los cuales llegaban otros productos más minoritarios como era el caso de los metalúrgicos.

Abrahim estaba establecido en Murcia en 1470, aunque sin la condición jurídica de vecino que alcanzó en 1471; decidido a instalarse en la morería de la Arrixaca, recibió permiso en 1472 para levantar un obrador entre la muralla de la ciudad y la cerca exterior del barrio, en un solar situado a la izquierda de la salida de la puerta del Azoque, por el cual se convirtió en censatario del concejo con el pago de 1 real de plata valenciano, unos 25 mrs.; con él se

40. Libro de clavario $1407-1408$, f. $4 \mathrm{r}$ y siguientes hasta el de 1438-1439. M. ${ }^{\mathrm{a} C}$. VEAS ARTESEROS, La hacienda concejil..., A.d. f. 349.

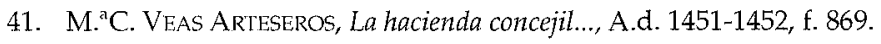

42. A.C. 1448 , f. 32v (1448-XI-26). M. ${ }^{2}$ C. VeAs ARTESEROs, La hacienda concejil..., A.d. 1447-1448 (1447-IX-23). 
había instalado su numerosa familia, constituida por su mujer y varios hijos y nietos ${ }^{43}$ :

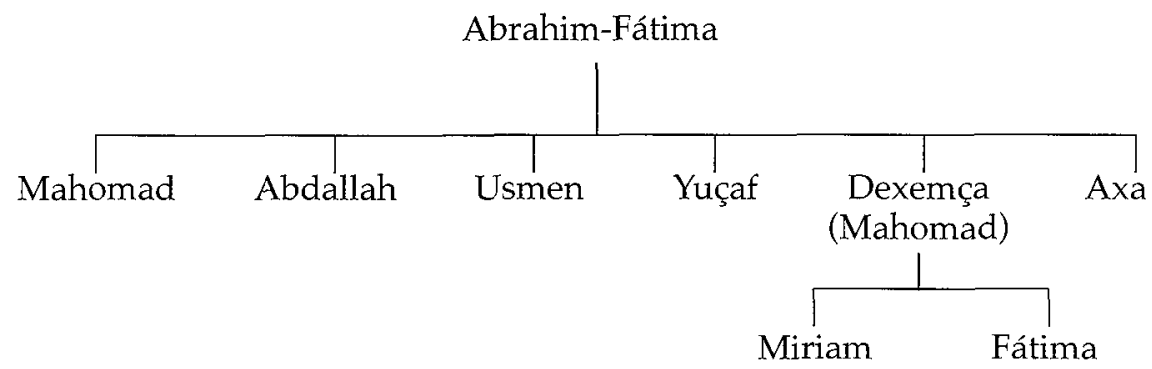

Desde muy pronto, la familia a través de uno de los hijos varones, innominado, se vio envuelta en una serie de pendencias que tuvieron como punto en común la posesión de un caballo: o bien sufrió el robo del animal a manos de un cristiano o bien fue el autor de la muerte de otro que era propiedad de un reconocido murciano; mientras en el primer caso la pesquisa de los alcaldes no dio resultado y no parece que el caballo se recuperara, cuando el hijo de Abrahim fue el autor el concejo obligó al alcalde de la morería, Abrahim Alhajar, a rectificar una sentencia que favorecía a Mexía, porque no quiso contar con la declaración de unos testigos de la parte contraria que pertenecían a distinta jurisdicción, la eclesiástica de Alcantarilla; la sentencia definitiva de los alcaldes de la ciudad condenó a Mexía a pagar una indemnización de $6.000 \mathrm{mrs}$. al propietario del caballo, Ruy García de Cáceres, frente a los 7.000 que éste reclamaba ${ }^{44}$.

Desde su llegada de Belmonte, la posesión de un caballo era el principal capital de la familia, al margen de las herramientas de su trabajo, y las peripecias en las que se vieron envueltos a través de un hijo, nunca concretado, dificultaron su instalación definitiva, como demuestra que en 1473 el taller, que un año antes se les había concedido, aún estuviese sin construir y que unos años después, en 1477, el hijo de Mexía llegase a ser desterrado tres meses a dos leguas de la ciudad, junto a "Maestrico", por ser "bolliçiosos e reboluedores de questiones e enojos en la dicha çibdad e en su morería...", víctima de lo cual había sido herido el también herrero Alí Cheleni; el incumplimiento reiterado del destierro fue la causa de que le fuese ampliado a seis meses, que definitivamente acabó cumpliendo ${ }^{45}$.

43. A.C. 1470 , f. $65 \mathrm{r}$ (1470-XI-6), 89v (1471-II-12); 1471, f. 93v (1472-VI-20).

44. A.C. 1472, f. 64r (1472-X-13), 66v (1472-X-17), 67v (1472-X-20), 69r (1472-X-24). En 1381 llegaba temporalmente a Murcia como calderero-buhonero un nuevo miembro de la familia de origen, Hamete Mexía, A.C. 1480, f. 139v (1481-IV-28).

45. A.C. 1473 , f. 12r (1473-VI-26); 1476, f. 97r (1477-III-4), 108r (1477-III-31) y 1477, f. 54r (1477X-4), M. ${ }^{a}$ C. Veas Arteseros, Mudéjares murcianos..., p. 25. 
Las duras condiciones de vida de una exigua minoría mudéjar en un medio ambiente hostil por parte de la sociedad castellana se unían a la pura competitividad de los profesionales instalados en la morería durante varias generaciones, frente a los que intentaban instalarse en circunstancias poco propicias, siendo el resultado de ello las luchas internas que se reflejaban en sus relaciones con los cristianos y producían la intervención concejil que queda simbolizada en los calificativos de "bolliçioso e reboluedor de roydos..." 46 , con que se calificaba al hijo de Mexía, a su vez autor y víctima de unos hechos que escapaban completamente a un control individual y familiar.

\section{Temblús}

Reconocibles en la segunda mitad del siglo XV a través de cuatro miembros de una familia de herreros y torneros.

El herrero Alí fue copartícipe en 1447 de los trabajos de construcción de la lombarda junto a Abrahim Alhajar, Mahomad Chelvi (I) y otros herreros de la ciudad con la categoría de "maestro de hacer lombardas", cuando llevaba mucho tiempo fabricando para el concejo todo tipo de ferretería instrumental, actividad en la que continuó hasta 144947.

Çad, también herrero y trabajador en la lombarda, en condiciones de inferioridad respecto a Alí, cuando ya en años anteriores había desempeñado funciones de confianza como la de recaudador de monedas; su presencia se prolonga documentalmente hasta 1455 abasteciendo al concejo de material para el arreglo de algunas puertas de la ciudad ${ }^{48}$; posible hermano de Alí.

El más inconcreto de todos los miembros de la familia es Yusuf, solamente perceptible a través del trabajo colectivo de 1447 que fue la construcción de la lombarda ${ }^{49}$ y de parentesco desconocido.

En contraposición, el más conocido de todos los Temblús fue Alí (II), tornero, identificado por su matizada especialización respecto a la generación anterior y el tiempo transcurrido, suficiente para que se hubiese producido un relevo generacional, en el que el nuevo Alí aportó también su reconocida condición de alfaquí; no es posible ignorar la degradación sufrida por la sociedad mudéjar y su dependencia respecto a la cristiana, al contemplar a

\footnotetext{
46. A.C. 1476, f. 112v (1477-IV-14).

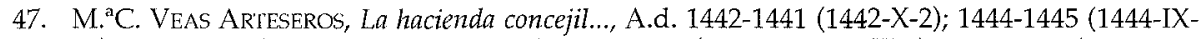
19); 1445-1446 (1445-IX-6, X-21, XI-24); 1446-1447 (1446-VIII-3, XII-4); 1447-1448 (1447-VII$30, X-11)$ y $1449-1450(1449-X I I-29)$.

48. Ibídem, A.d. 1438-1439 (1439-II-25), 1455-1456 (1455-X-6 y XII-8).

49. Ibídem, A.d. 1447-1448 (1447-VIII-29).
} 
todo un experto en la ley coránica participando en la construcción de los tronos con los que se celebraba la festividad del Corpus entre los cristianos: en 1471 hizo para el entremés del Juicio cuatro "aros de torno" para la nube y el cielo del Paraíso y otros dos para "la boca del Infierno" 50 .

$$
\star \star \star
$$

\section{APÉNDICE}

Utensilios fabricados por los herreros murcianos, con la función documentada.

Agujas para las puertas de la muralla.

Aldabas. Piezas metálicas fijas en la pared para sujetar los reos a la pared en la mazmorra.

Alfardones. Anillos metálicos utilizados en los quicios de las puertas y en la cabría.

Almacén. Conjunto de municiones y pertrechos de guerra.

Armellas. Anillos de hierro u otro metal que tienen una espiga o tornillo para fijarlos a los grillones.

Arpones para las escalas utilizadas en los asaltos bélicos.

Azadones.

Cabría. Máquina para levantar pesos.

Cadenas.

Candados.

Carruchas.

Ceños. Aros metálicos para ceñir la lombarda.

Cerraduras.

Cinceles para liberar a los presos de la cárcel.

Clavijas con sus "caderas" para la lombarda.

Clavos de diverso tamaño.

Cuchillos "blancos", ofensivos y de monte.

Chapas de hierro para las puertas.

Gafas o grapas. Piezas de metal para sujetar las piedras en las reconstrucciones del puente mayor y para la gata.

Gata. Máquina para levantar pesos a poca altura.

Gorrones. Espigas en las que terminaba el extremo inferior de un eje vertical, utilizadas para la rotación de puertas.

50. Ibidem, A.d. 1465-1466 (1465-X-1); 1469-1470 (1470-V-26) y 1470-1471 (1471-VI-6 y 8). 
Goznes para los manteles.

Harropeas o herropeas. Grilletes para sujetar a los presos por los pies.

Hebillas para tirar de la gata.

Hogares o cocinas de hierro.

Llaves.

Manteletes. Tabla gruesa con la que se cubría la boca de un trueno de artillería cargado para derribar una puerta o pared.

Martillos.

Perpales o pérpalos. Barras gruesas para levantar pesos.

Pesas.

Piezas, ruedas y barras, para el reloj.

Rejas.

Tacos para la lombarda.

Tijeras podaderas y de esquilar.

Púas.

Viratones o virotes. Hierro largo, a modo de maza, que se colgaba de la argolla sujeta al cuello de los esclavos para que no escapasen.

\section{RESUMEN}

Desde el siglo XIII la actividad de los herreros mudéjares fue imprescindible para el concejo de Murcia, para el que actuaron como continuos proveedores hasta los años setenta del siglo XV; ello les proporcionó un nivel socioeconómico superior al de sus convecinos de la morería, materializado en el desempeño casi continuo de las funciones institucionales de alcaides y alcaldes de la misma por parte de varias familias, que llegaron a ser auténticos linajes locales dentro de la exigua y pobre minoría mudéjar de la ciudad. De ello se derivó la existencia de dos corrientes internas que defendían o rechazaban hasta con la violencia la instalación en la morería de artesanos forasteros, estando los primeros respaldados por los alcaides-herreros y el concejo ciudadano del que éstos dependían, generalmente en oposición a los artesanos ya instalados, que se negaban a una competencia considerada peligrosa para la pobreza del mercado local.

Veinte años antes de la caída de Granada, la comunidad mudéjar murciana había alcanzado unas cotas de debilidad interna y sometimiento a la sociedad cristiana que sus pocos herreros-dirigentes estaban inmersos en un proceso de sujeción irreversible, siendo el símbolo de este ocaso el hecho de que todo un alfaquí, el tornero Alí Temblús (II), en 1471 trabajara en la fabricación de piezas para la escenificación de un entremés sobre el Juicio Final 
que se representó en la Festividad del Corpus, indiscutible símbolo de la cultura cristiana del siglo XV.

\section{ABSTRACT}

From the 13th century the activity of the Mudejar blacksmiths was essential for the council of Murcia. As they went on providing the council until the seventies of the 15th century, they obtained a socio-economic level superior to that of their neighbours in the Moorish quarter. It was materialised in the almost continuous performance of the institutional functions of wardens and mayors by several families, which became authentic local noble families among the scanty and poor Mudejar minority in the city. This fact brought the existence of two internal currents, which defended or rejected -even with the use of violence- the installation of foreign craftsmen in the Moorish quarter. Being the first supported by the warden-blacksmiths and the citizen council they depended on, generally in opposition to the already settled craftsmen, who refused a competition considered dangerous for the poverty of the local market.

Twenty years before the loss of Grenada, the Mudejar community in Murcia had reached such internal weakness levels and submission to the Christian society that its few blacksmith-rulers were irreversibly in their hands. Being the symbol of this decline the fact that a real "alfaqui", the turner Alí Temblús II, manufactured the pieces to set on stage an interlude on the Final Judgement, in 1471. Which was represented in the Festivity of the Corpus, unquestionable symbol of the Christian culture of the 15th century. 